\title{
Developing Surrogate Markers for Predicting Antibiotic Resistance "Hot Spots" in Rivers Where Limited Data Are Available
}

\author{
Amelie Ott, Greg O’Donnell, Ngoc Han Tran, Mohd Ridza Mohd Haniffah, Jian-Qiang Su, \\ Andrew M. Zealand, Karina Yew-Hoong Gin, Michaela L. Goodson, Yong-Guan Zhu, \\ and David W. Graham*
}

Cite This: Environ. Sci. Technol. 2021, 55, 7466-7478

Read Online

\section{ACCESS | \\ Wl Metrics \& More \\ Article Recommendations \\ Supporting Information}

ABSTRACT: Pinpointing environmental antibiotic resistance (AR) hot spots in low-and middle-income countries (LMICs) is hindered by a lack of available and comparable AR monitoring data relevant to such settings. Addressing this problem, we performed a comprehensive spatial and seasonal assessment of water quality and AR conditions in a Malaysian river catchment to identify potential "simple" surrogates that mirror elevated AR. We screened for resistant coliforms, 22 antibiotics, $287 \mathrm{AR}$ genes and integrons, and routine water quality parameters, covering absolute concentrations and mass loadings. To understand relationships, we introduced standardized "effect sizes" (Cohen's D) for AR monitoring to improve comparability of field studies. Overall, water quality generally declined and environmental AR levels increased as one moved down the catchment without major seasonal variations, except total antibiotic concentrations that were higher in the dry season (Cohen's $\mathrm{D}>0.8, P<0.05$ ). Among simple surrogates, dissolved oxygen (DO) most strongly correlated (inversely) with total AR gene concentrations (Spearman's $\rho$ 0.81, $P<0.05$ ). We suspect this results from minimally treated sewage inputs, which also contain AR bacteria and genes, depleting DO in the most impacted reaches. Thus, although DO is not a measure of AR, lower DO levels reflect wastewater inputs, flagging possible AR hot spots. DO measurement is inexpensive, already monitored in many catchments, and exists in many numerical water quality models (e.g., oxygen sag curves). Therefore, we propose combining DO data and prospective modeling to guide local interventions, especially in LMIC rivers with limited data.

KEYWORDS: antibiotic resistance, LMICs, SE Asian rivers, water quality, environmental monitoring, high-throughput qPCR, modeling

\section{INTRODUCTION}

Increasing resistance in microorganisms to antibiotics and other drugs poses a global health threat. ${ }^{1}$ When a pathogen becomes resistant to critical drugs, formerly easy-to-treat infections can be lethal. ${ }^{2,3}$ Consequently, scientists and policy makers must better understand drivers of antibiotic resistance (AR) to reduce its global spread. The number of peer-reviewed AR papers has tripled in the last 10 years (title or abstract containing "antibiotic resistance" web of science from 2009 to 2019) with more than 10000 papers published in 2019 alone. However, our understanding of environmental AR spread lags behind other contexts. ${ }^{4}$ When insufficiently treated wastewater enters rivers, residues of antibiotics, antibiotic-resistant bacteria (ARBs), and antibiotic-resistant genes (ARGs) can radiate through the environment, potentially posing an exposure risk. ${ }^{5,6}$ However, mitigating environmental AR spread is hindered by many factors, including: (1) inadequate data to make decisions about environmental AR exposures; (2) the complexity and diversity of environmental matrices; (3) conflicting definitions of $\mathrm{AR}$ and inconsistency in measuring methods; (4) reliance on overly expensive detection methods; (5) limited agreement on AR thresholds of possible concern; and (6) a limited understanding of how environmental AR levels translate to human health risk.

Limited data and expensive AR detection methods are especially problematic in low- and middle-income countries (LMICs), particularly identifying sites of greatest concern. ${ }^{8}$ This is partly because most studies are more academic rather than practical and also because researchers overly focus on testing statistical significance ( $P$ values) to report spatial or temporal differences. A lower $P$ value is often interpreted as meaning a bigger difference between two settings, but

Received: February 9, 2021

Revised: April 30, 2021

Accepted: May 3, 2021

Published: May 17, 2021

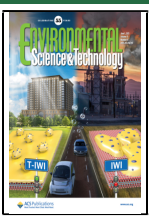


statistical significance only means that it is unlikely for the null hypothesis to be true (such as $H_{0}=$ no difference in antibiotic concentration between up- and downstream river locations), ${ }^{9}$ which often has limited value in quantifying the scale of differences.

In contrast to $P$ values, we feel "standardized dimensionless effect sizes" better describe the size of differences and allow comparison of studies from different settings with different variables. ${ }^{10}$ Effect sizes are easy to calculate and, unlike $P$ values, provide a comparison independent of sample size. ${ }^{10}$ Surprisingly, despite the popularity of effect size in metaanalysis and psychological studies, they have not been used in $\mathrm{AR} /$ water quality studies. We argue that to effectively interpret and compare AR levels, both statistical significance ( $P$ value) and substantive significance (standardized effect size with confidence intervals) should be reported. ${ }^{10}$

Increasing the informative value of monitoring data is especially critical in LMICs. While antibiotic use per person is increasing in LMICs compare with high-income countries (HIC), sewage treatment lags behind. ${ }^{1-13}$ Southeast (SE) Asia with its rapid economic development has been proposed as an epicenter for emerging infectious diseases and $\mathrm{AR}^{14-16}$ In particular, extended-spectrum $\beta$-lactamase (ESBL)-producing and carbapenem-resistant pathogens pose major health threats in the region. ${ }^{17,18}$ ESBL bacteria produce an extendedspectrum enzyme that breaks down the majority of $\beta$-lactam antibiotics such as penicillin. ${ }^{17}$ Infections with ESBL bacteria are treated with the remaining $\beta$-lactam antibiotics, called carbapenems. ${ }^{17}$ High rates of mortality occur when pathogens become resistant to these last-resort antibiotics. ${ }^{17}$

Malaysia, our study site here, has one of the fastest-growing economies in SE Asia. ${ }^{19}$ Increased wealth has allowed more Malaysians to access healthcare, including antibiotics. A national study in 2014 found that antibiotics were prescribed in $21 \%$ of patient encounters, although $46 \%$ of these were for upper respiratory tract viral infections, where antibiotics are often not suitable. ${ }^{20}$ In 2000, a National Surveillance of Antibiotic Resistance (NSAR) programme was initiated to monitor AR bacteria in hospitals. ${ }^{21}$ Particular local concern are increasing ESBL-producing Enterobacteriaceaea and carbapenem-resistant pathogens, which underpins our focus herein on the environmental spread of ESBL strains and related ARGs. ${ }^{22}$

Despite LMICs carrying a higher burden of AR, including Malaysia, environmental AR surveillance is lacking. ${ }^{12}$ As such, there is a shortage of data in most LMICs, especially the relative susceptibility of local populations to the effects of AR due to limited accurate health surveillance data. ${ }^{8,23}$ AR transmission models have been proposed to estimate the risk of $\mathrm{AR}^{24}$ but environmental AR modeling, which might help fill in data gaps in LMICs, lags far behind. ${ }^{25}$ While surface water quality models have existed for decades, ${ }^{26}$ a few attempts have been made to model AR spread in watersheds, ${ }^{27-29}$ often hindered by limited knowledge of AR fate processes in the environment, and missing AR and/or hydrological calibration data.

The aim of this study was to identify easy-to-measure water quality surrogates that would aid monitoring and modeling of AR in locations with limited data. For this, we examined the Skudai river catchment in Malaysia, using simple AR culturing methods and routine water quality markers in parallel to more sophisticated methods. Further, we show the value of effect sizes for environmental AR studies, which better account for spatial, seasonal, and dilution effects, as well as improve comparability of monitoring studies in LMICs and HICs.

\section{MATERIAL AND METHODS}

Catchment Description. The Skudai river catchment in southern Malaysia (total drainage area $288 \mathrm{~km}^{2} ;{ }^{30}$ see Supporting Information (SI) Figure S1) is composed of urban/developed, agricultural ( $80 \%$ oil palm, $20 \%$ rubber plantations), and forest land in roughly equal proportions. ${ }^{31}$ The Skudai catchment lays within the Johor Bahru district $\left(1865 \mathrm{~km}^{2}\right.$ with 1.4 million inhabitants $\left.{ }^{32}\right)$. Similar to many LMIC settings, sewage treatment in the Skudai catchment is inconsistent, sometimes with poorly defined discharge locations. ${ }^{33,34}$ National data from 2017 show $79 \%$ of the Malaysian population connected to sewers with $20 \%$ serviced by septic tanks and $<1 \%$ relying on latrines and other. ${ }^{35}$ Improvement to secondary (biological) treatment has taken place in some areas, ${ }^{36}$ but many suburban locations (such as within the Skudai catchment) still rely on septic tanks. To our knowledge, no major pharmaceutical production facilities are located in the catchment. ${ }^{34}$

The main Skudai river $(42.8 \mathrm{~km})$ passes rural and urban areas before it discharges into the sea. The Skudai has several tributaries, including the mostly rural Senai $(11.8 \mathrm{~km})$ and urbanized Melana $(18.7 \mathrm{~km}) .^{30}$ Malaysia has a humid tropical climate and two monsoon seasons, the relatively dry Southwest Monsoon from May to September and the wetter Northeast Monsoon from November to March, but rainfall also occurs in the transitional periods. ${ }^{37,38}$

Sample Collection and Processing. River water samples were collected from eight sampling points in the Skudai catchment (SI Figure S1 and Table S1) across four seasonal sampling campaigns: two in March 2018 (trips I and II) in the "wet season" and two in July 2018 (trips III and IV) during the "dry season". The eight points were chosen based on land use and preliminary sampling data from 15 sites (results not shown) and included six locations on the Skudai itself (S1, S2, S5, S6, S7, and S8 during trips I-IV) and two sites on Senai and Melana tributaries (Se1 and M5; sampled during trips I, III, and IV), respectively. The campaign resulted in 30 samples from which technical triplicates were obtained.

Sampling events always were conducted over a single day in the morning, from up- to downstream, only at low tide, and on days when rainfall had not occurred within $24 \mathrm{~h}$. Each sampling location was at a bridge, which allowed water collection from mid-river. Samples were collected in a prerinsed clean bucket (on a rope), waiting 2 min between taking each replicate. Sample water was stored in autoclaved glass bottles on ice in the dark $(3 \times 1 \mathrm{~L}$, except $4 \times 1 \mathrm{~L}$ for S1 to assure sufficient DNA yield for downstream processes). In the laboratory, technical replicates were processed separately, splitting $1 \mathrm{~L}$ of sample into $15 \mathrm{~mL}$ for chemical analysis, $2 \mathrm{~mL}$ for coliform plating, $500 \mathrm{~mL}$ for antibiotic analysis, and $80-$ $250 \mathrm{~mL}$ for DNA extraction.

River water temperature, dissolved oxygen (DO), $\mathrm{pH}$, and conductivity were measured on-site with an HQ40D portable multimeter (Hach). Conductivity was temperature-corrected $\left(\mathrm{NaCl}\right.$ nonlinear with reference temperature $\left.25{ }^{\circ} \mathrm{C}\right)$. River volumetric flowrates were estimated using the float method with an estimated accuracy of $\pm 20 \%{ }^{39,40}$ River width and depth were used to calculate cross-sectional area at the time of sampling at each point, which was multiplied by the measured 
surface velocity to obtain the flowrate. A factor of 0.85 corrected for surface velocity data. ${ }^{39,40}$

Chemical Analysis. Water samples were filtered through $0.2 \mu \mathrm{m}$ polyethersulfone (PES) syringe filters (VWR) and stored for a maximum of $24 \mathrm{~h}$ at $4{ }^{\circ} \mathrm{C}$ prior to chemical analysis. Ammonia $\left(\mathrm{NH}_{3}-\mathrm{N}\right.$, salicylate method $\left.{ }^{41}\right)$, chemical oxygen demand (COD, USEPA reactor digestion method ${ }^{42}$ ), total phosphorus (TP, USEPA PhosVer 3 with acid persulfate digestion method ${ }^{43}$ ), and total nitrogen $(\mathrm{TN}$, persulfate digestion method ${ }^{44}$ ) were measured using commercial colorimetric test kits with a UV-vis spectrophotometer DR5000 (all Hach). Where necessary, the samples were diluted with Milli-Q water prior to analysis.

The Malaysian Department of Environment (DOE) applies a Water Quality Index with three classifications ("clean", "slightly polluted" and "polluted") and the National Water Quality Standards for Malaysia (classes I-V) to evaluate river water quality based on selected parameters. ${ }^{45}$ Combining both approaches, three water quality categories were created based on $\mathrm{COD}, \mathrm{NH}_{3}-\mathrm{N}$, and DO concentrations in the catchment: clean (class I), slightly polluted (class II), and polluted (class III-V) (SI Table S2). We compiled chemical data from S1 and S8 with national DOE river water quality data collected for the same locations throughout 2018 (SI Table S3).

Coliform and Other Plating. Coliform ChromoSelect agar was used to quantify colony forming units (CFUs) of total coliform (TC), ESBL coliform (addition of ESBL supplement to agar), and carbapenem-resistant bacteria (CPB-0.5 and CPB-2; addition of meropenem in dimethyl sulfoxide (DMSO) to agar at final concentrations of 0.5 and $2 \mu \mathrm{g} /$ $\mathrm{mL}$ ) (all Sigma-Aldrich). Each ESBL plate contained following antibiotics in final concentrations: ceftazidime $(3 \mu \mathrm{g} / \mathrm{mL})$, cefotaxime $(3 \mu \mathrm{g} / \mathrm{mL})$, ceftriaxone $(2 \mu \mathrm{g} / \mathrm{mL})$, aztreonam $(2$ $\mu \mathrm{g} / \mathrm{mL})$, fluconazole $(10 \mu \mathrm{g} / \mathrm{mL}) .{ }^{46}$ Meropenem concentrations were selected based on preliminary screening experiments ${ }^{47}$ and the intermediate meropenem CLSI minimum inhibitory concentration (MIC) breakpoint for Enterobacteriaceae of $2 \mu \mathrm{g} / \mathrm{mL}^{48}$ ChromoSelect agar allowed visual differentiation of presumptive Escherichia coli (subsequently referred to as $E$. coli ${ }^{49}$ ) versus other coliforms. Where necessary, water samples were diluted with sterile phosphatebuffered saline (VWR) to achieve 30-300 CFU per plate in three technical replicates. ${ }^{50}$ Each plate was provided 100 or $200 \mu \mathrm{L}$ of sample and incubated at $37{ }^{\circ} \mathrm{C}$ for $24 \mathrm{~h}$. Negative controls and blanks were intermittently tested to verify that inlab contamination was minimized. CPB- 2 were only measured for trips II-IV.

Antibiotics Analysis. Solid-phase extraction (SPE) coupled with ultrahigh-performance liquid chromatographytandem mass spectrometry (UHPLC-MS/MS) was used to quantify 22 antibiotics belonging to seven classes: $\beta$-lactams, lincosamides, macrolides, quinolones/fluoroquinolones, sulfonamides, tetracyclines, and others (see the SI for details and Tables S4 and S5). River antibiotic concentrations were compared to predicted no effect concentrations (PNECs). ${ }^{51}$ PNECs are predictive indicators and only provide a relative sense of possible selection.

Antibiotic-Resistant Gene Quantification. River samples were analyzed using high-throughput quantitative polymerase chain reaction (HT-qPCR) for 283 ARGs (36 aminoglycosides, $52 \beta$-lactams, nine fluoroquinolone (FCA, quinolone, florfenicol, chloramphenicol, and amphenicol ARGs), 46 MLSB (macrolide-lincosamide-streptogramin B
ARGs), 51 nonspecific efflux pumps, seven sulfonamides, 39 tetracycline, 32 vancomycin, 11 others), 12 mobile genetic elements (MGEs; eight transposases, four integrases), and one $16 \mathrm{~S}$ rRNA gene (SI Table S6).

The water samples were filtered onto $0.22 \mu \mathrm{m}$ cellulosenitrate filters (Sartorius) to extract DNA with the FastDNA SPIN kit for soil (MP Biomedicals). Filtration volume varied depending on the sampling point (3 technical replicates of 80$250 \mathrm{~mL}$ each) with more water being filtered from upstream location S1 to collect sufficient DNA. The product DNA was cleaned with the QIAquick Nucleotide Removal Kit (Qiagen). DNA quality and quantity were measured with the NanoDrop and Qubit dsDNA HS assay (both Thermo Fisher Scientific), respectively. DNA absorbance ratios were 260/280 > 1.8 and $260 / 230>1.5$. Replicate samples were pooled in equal DNA aliquots to reach $2 \mu \mathrm{g}$ DNA and freeze-dried prior to further analysis. Between analysis steps, DNA was stored at $-20{ }^{\circ} \mathrm{C}$.

HT-qPCR was performed with SmartChip Real-Time PCR (Wafergen) as previously described. ${ }^{52,53}$ Amplification efficiency always was between 90 and $110 \%$ and detection only was confirmed when all three technical replicates were positive. Relative copy number of ARGs and MGEs were calculated and transformed to absolute copy numbers by multiplying with $16 \mathrm{~S}$ rRNA concentration for each sample. ARG and MGE cell concentrations were estimated by dividing the 16S rRNA concentration by 4.1 , the estimated average $16 \mathrm{~S}$ rRNA gene copy number per bacterium. ${ }^{54}$

Statistical Analysis and Data Visualization. Data can be accessed through the Center for Open Science, OSF (Ott, Amelie. 2021. "Monitoring and Modeling of Antibiotic Resistance in Southeast Asian Rivers”. OSF. https://osf.io/ gcpky/?view_only=90e614c2c6b64483aa503694af113789). Statistical analysis was performed in $\mathrm{R}^{55}$ Graphics were created using R package ggplot 2 version $3.3 .3^{56}$ and finalized in Inkscape. ${ }^{57}$ The Skudai catchment map was composed in ArcGIS version 10.6.1. ${ }^{58}$ The river catchment was extracted through digital elevation model (DEM) slope analysis. ${ }^{59}$ Mass loading data was calculated by multiplying concentration data with the corresponding measured discharge $\left(\mathrm{m}^{3} / \mathrm{s}\right)$ for each sampling site and trip.

The substitution method R2D was used to allow statistical analysis of left-censored data (e.g., antibiotic and coliform data). ${ }^{60}$ For this, measurements under detection limit were substituted with $\sqrt{ } 2 / 2$ times the limit of detection, but only if less than $40 \%$ of all data points were under the detection limit. ${ }^{60}$ Parameters with higher rates of "nondetects" were excluded from statistical analyses. Averages are reported as the mean with \pm standard deviation (based on three or four biological replicates) throughout the paper.

Statistical significance testing employed $P$ values and calculated Cohen's D effect sizes ${ }^{61,62}$ to assess spatial and seasonal differences in water quality and AR parameters. Large statistically significant spatial or seasonal effects were defined for values of Cohen's $\mathrm{D}<-0.8$ or $>0.8$ and $P<0.05$. $^{61}$ Effect sizes can be negative or positive, depending on which mean is greater. Wet vs dry season data were compared with paired $t$ tests and corresponding Cohen's Ds (eq 1). Up- (S1) vs downstream (S8) data were compared with Welch's $t$-tests ${ }^{63}$ and corresponding Cohen's Ds (eq 2). 

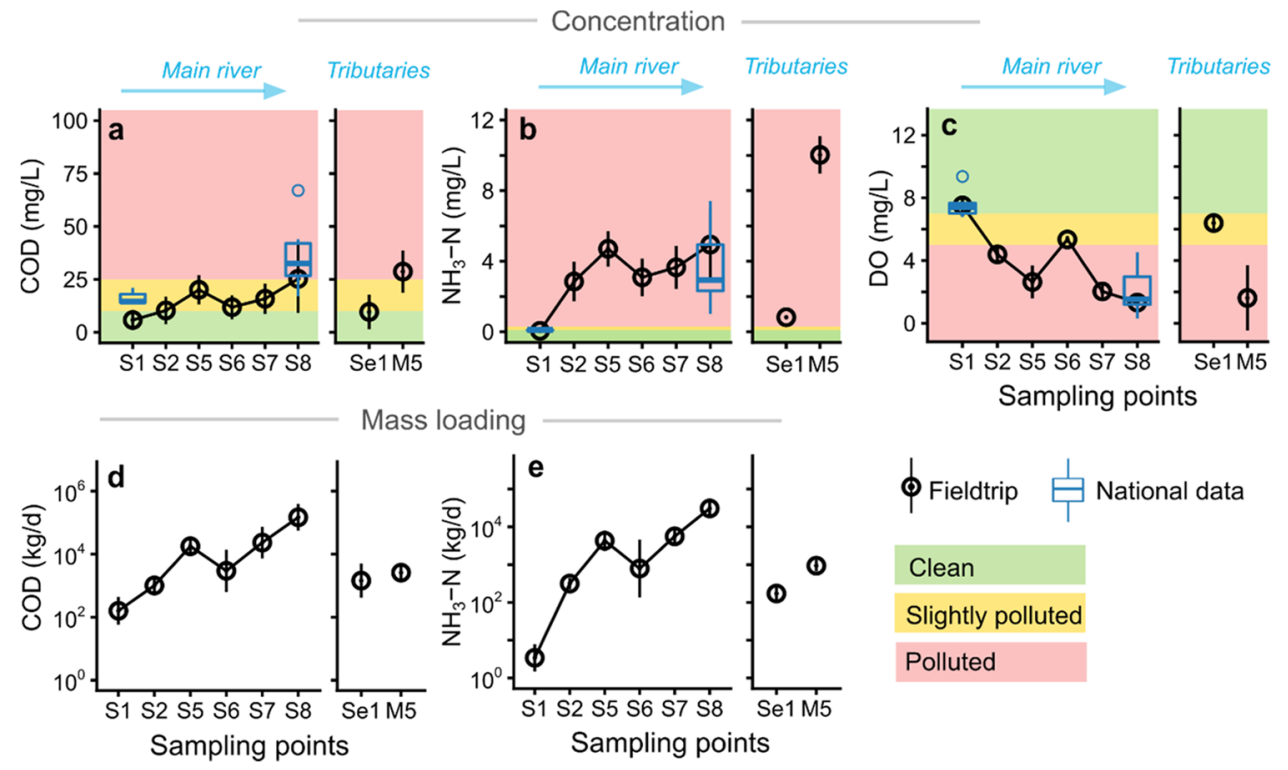

Figure 1. Chemical oxygen demand (COD; a, d), ammonia $\left(\mathrm{NH}_{3}-\mathrm{N} ; \mathrm{b}, \mathrm{e}\right)$, and dissolved oxygen (DO, c) concentrations (a-c) and mass loadings $(\mathrm{d}, \mathrm{e})$ in the river catchment. Data represented is based on four biological replicates for the main river (S1, S2, S5, S6, S7, and S8) and on three biological replicates for the tributaries (Se1, M5). Concentrations were compared to Malaysian water quality thresholds and Department of Environmental (DOE) monitoring data for S1 (DOE sampling point 3SI09) and S8 (DOE sampling point 3SI05). d: day.

Cohen's D effect size for paired $t-$ test

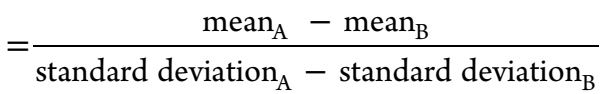

$$
\begin{aligned}
& \text { Cohen's D effect size for Welch's } t-\text { test } \\
& =\frac{\text { mean }_{\mathrm{A}}-\text { mean }_{\mathrm{B}}}{\sqrt{\left(\text { variance }_{\mathrm{A}}+\text { variance }_{\mathrm{B}}\right) / 2}}
\end{aligned}
$$

Benjamini-Hochberg P-adjustment was applied to correct for multiple testing. ${ }^{64}$ Cohen's Ds were calculated with the "cohen.d" function in the $\mathrm{R}$ package effsize version 0.8.1. ${ }^{65}$ Normality was assessed with the Shapiro-Wilk test. Where necessary, parameters were transformed using the Box-Cox transformation, ${ }^{66}$ as implemented in the "boxcox" function in the $\mathrm{R}$ package MASS version $7.3-53.1^{67}$ (SI Table S7). To visualize spatial and seasonal effects, Cohen's D effect sizes were plotted against $P$ values for each parameter in volcano plots, using the R package EnhancedVolcano version 1.8.0. ${ }^{68}$ To analyze water quality and AR parameter associations, Spearman's correlations were calculated with Benjamini-Hochberg multiple testing correction, using $\mathrm{R}$ packages psych version 2.1.3 ${ }^{69}$ and corrplot version $0.84 .^{7}$

\section{RESULTS}

Water Quality and Microbiology. Water quality conditions in the catchment were characterized by generally low DO, high COD, and very high $\mathrm{NH}_{3}-\mathrm{N}$ concentrations based on national Malaysian thresholds (Figure 1a-c, SI Tables S8-S10). Water quality declined in the Skudai from upstream being clean/slightly polluted (S1: $7.5 \pm 0.5 \mathrm{DO} \mathrm{mg} /$ $\left.\mathrm{L}, 0.05 \pm 0.03 \mathrm{NH}_{3}-\mathrm{N} \mathrm{mg} / \mathrm{L}, 5.8 \pm 4.8 \mathrm{COD} \mathrm{mg} / \mathrm{L}\right)$ to downstream being slightly polluted/polluted (S8: $1.3 \pm 0.3 \mathrm{mg}$ $\left.\mathrm{DO} / \mathrm{L}, 4.9 \pm 2 \mathrm{NH}_{3}-\mathrm{N} \mathrm{mg} / \mathrm{L}, 25.3 \pm 16 \mathrm{COD} \mathrm{mg} / \mathrm{L}\right)$. Measurements for DO, COD, and $\mathrm{NH}_{3}-\mathrm{N}$ aligned well with the national 2018 DOE monitoring data (Figure 1a-c).

Total coliform and $\beta$-lactam-resistant coliform concentrations all increased from upstream $S 1\left((1.1 \pm 0.5) \times 10^{3} \mathrm{TC}\right.$
$\mathrm{CFU} / \mathrm{mL},(1.5 \pm 1.3) \times 10^{2} \mathrm{ESBL}$ coliform CFU $/ \mathrm{mL},(3.1 \pm$ $\left.4.1) \times 10^{1} \mathrm{CRB}-2 \mathrm{CFU} / \mathrm{mL}\right)$ to downstream S8 $((4.1 \pm 3.3) \times$ $10^{4} \mathrm{TC} \mathrm{CFU} / \mathrm{mL},(4 \pm 4.1) \times 10^{3} \mathrm{ESBL}$ coliform $\mathrm{CFU} / \mathrm{mL}$, $\left.(1.1 \pm 0.2) \times 10^{2} \mathrm{CRB}-2 \mathrm{CFU} / \mathrm{mL}\right)$ in the Skudai river (Figure S2 and Table S11). Across the catchment, we observed an approximately one $\log _{10}$ difference between TC $>$ ESBL coliform $>$ CRB- 2 concentrations, meaning that $\sim 10 \%$ of total coliform produced ESBL and $\sim 1 \%$ of total coliform were resistant to $2 \mu \mathrm{g} / \mathrm{mL}$ meropenem. E. coli and ESBL E. coli concentrations increased from upstream S1 $(3.5 \pm 2) \times 10^{1}$ $\mathrm{CFU} / \mathrm{mL}$ and $(<0.5-2) \times 10^{1} \mathrm{CFU} / \mathrm{mL}$, respectively, to downstream S8 $(2.8 \pm 2.1) \times 10^{3} \mathrm{CFU} / \mathrm{mL}$ and $(<0.1-5) \times$ $10^{2} \mathrm{CFU} / \mathrm{mL}$, respectively (Table S11).

Volumetric flowrate in the Skudai increased greatly from upstream (S1: $0.5 \pm 0.3 \mathrm{~m}^{3} / \mathrm{s}$ ) to downstream (S8: $82.7 \pm$ $30.7 \mathrm{~m}^{3} / \mathrm{s}$ ) with small variations observed between seasons (SI Table S8). Compared with concentration data, mass loadings showed much greater chemical and microbial pollutant transport down the Skudai river from rural to urban locations. $\mathrm{NH}_{3}-\mathrm{N}$ concentrations increased almost 100-fold from S1 to $\mathrm{S} 8$, whereas $\mathrm{NH}_{3}-\mathrm{N}$ mass loadings were $>14000$-fold greater along the same reach (SI Tables S9 and S10). Similarly, TC, ESBL coliform, CRB-0.5, and CRB-2 concentrations increased $10^{0}$ - to $10^{1}$-fold from $S 1$ to $S 8$ while mass loadings increased $10^{2}$ - to $10^{3}$-fold (SI Tables S11 and S12).

Interestingly, water and microbial quality improved slightly mid-stream at S6 for most parameters in concentrations and mass loadings (Figure 1, SI Figure S2). However, water quality was much poorer in the heavily urbanized Melana tributary (M5), both relative to the Skudai itself and the predominantly rural Senai tributary (Se1) (SI Tables S8, S9, and S11). As indicator of conditions, elevated CRB-2 and CRB-0.5 E. coli levels only were found in the Melana tributary across the catchment (SI Table S11).

Antibiotics Levels. Out of 22 antibiotics tested (SI Table S4), eight antibiotics (meropenem, cefixime, ceftazidime, erythromycin, chlortetracycline, minocycline, oxytetracycline, tetracycline) were not detected in the Skudai catchment. Six 
(a) Detected antibiotics for all sampling trips and sampling points

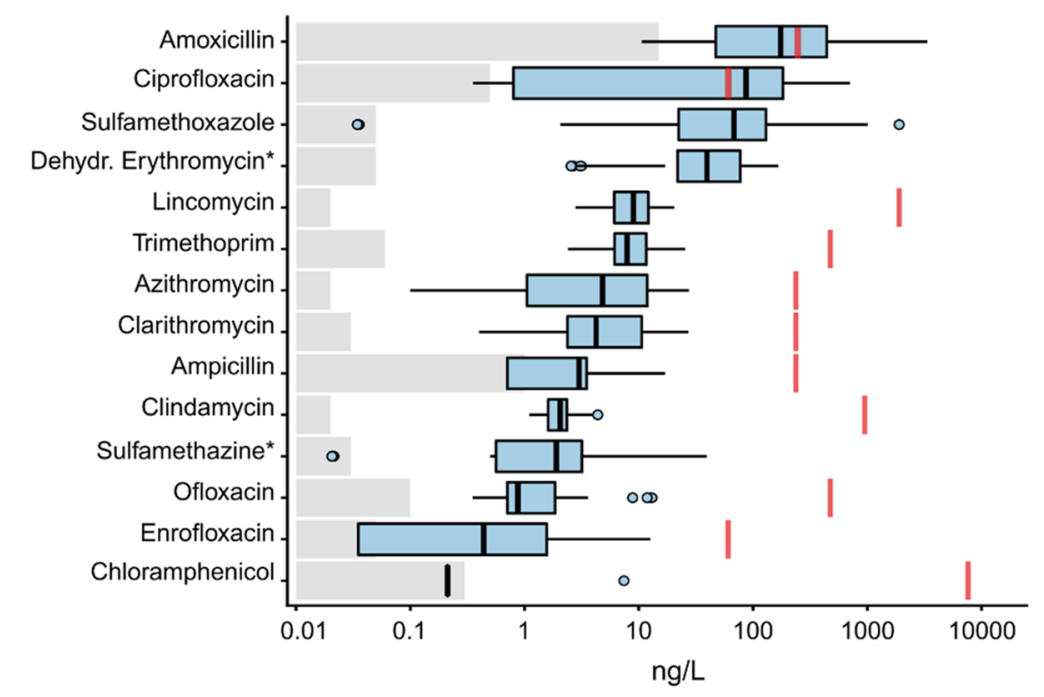

(b) Differentiation by season

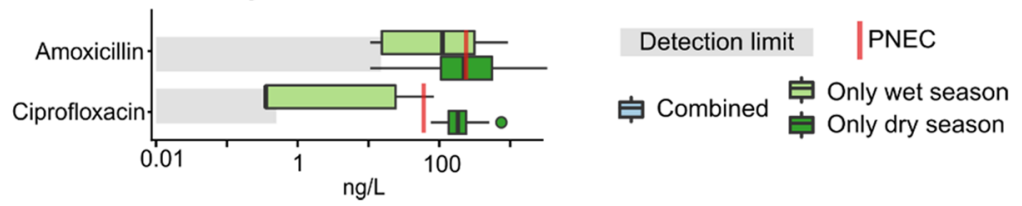

Figure 2. Antibiotic concentrations detected in the river catchment $(n=30)$ (a) with seasonal differentiation for amoxicillin and ciprofloxacin (b), compared to predicted no effect concentrations (PNEC). ${ }^{51}$

antibiotics/antibiotic derivates (clindamycin, lincomycin, azithromycin, clarithromycin, dehydrated erythromycin, trimethoprim) were detected in all river samples. Highest concentrations were observed for amoxicillin (all samples $510 \pm 906 \mathrm{ng} / \mathrm{L} ; \max 3336 \mathrm{ng} / \mathrm{L}$ at S2), sulfamethoxazole (all samples $181 \pm 383 \mathrm{ng} / \mathrm{L} ; \max 1933 \mathrm{ng} / \mathrm{L}$ at S8), and ciprofloxacin (all samples $131 \pm 162 \mathrm{ng} / \mathrm{L}$; $\max 705 \mathrm{ng} / \mathrm{L}$ at M5) with maximum values always detected in dry season samples (Figure 2). Only amoxicillin and ciprofloxacin were detected above PNEC values ${ }^{51}$ with all ciprofloxacin and 50\% of amoxicillin measurements in the dry season exceeding the PNEC thresholds.

In more than $40 \%$ of the samples, ampicillin and chloramphenicol concentrations were under the detection limit. Consequently, only 14/16 detected antibiotics were summarized into "total antibiotics" (SI Tables S9 and S10). Total antibiotics concentrations increased from up- (S1: 0.07 $\pm 0.05 \mathrm{mg} / \mathrm{L})$ to downstream (S8: $1.27 \pm 0.98 \mathrm{mg} / \mathrm{L})$ and were higher in the dry than wet season.

Antibiotic-Resistant Gene Abundances. We detected 210 different ARGs (74\% of assay) in the river catchment with 78 ARGs (28\% of those assayed) shared between all river water samples $(n=30)$. All 12 MGEs assayed were detected in the catchment with nine MGEs (75\% of assay) shared across all samples $(n=30)$. ARG and MGE levels increased from upto downstream in the Skudai river (SI Tables S13-S17), except for lower levels found mid-stream at S6 (Figure 3), which parallels water quality conditions based on other measured parameters.

The number of detected ARGs increased from $119 \pm 14$ at S1 to $150 \pm 8$ at S8 (SI Table S13). Increases in ARG diversity were most apparent at the top of the river. The most upstream site, rural S1, and the next site, semiurban S2, shared a core resistome of 157 ARGs and MGEs (Figure 4). However, only five unique ARGs were detected at $S 1$, whereas 41 unique ARGs (such as blaCTX-M and vanA) and 1 MGE were detected at S2.

On a wider scale, ARG and MGE concentrations increased more than $10^{2}$-fold from up- to downstream (S8: $1.2 \pm 0.9 \times$ $10^{8}$ ARG copies $/ \mathrm{mL}$ and $1.1 \pm 0.9 \times 10^{8} \mathrm{MGE}$ copies $\left./ \mathrm{mL}\right)$, while ARG and MGE mass loadings increased more than $10^{5}$ fold from up- to downstream (S8: $8.6 \pm 7.2 \times 10^{20}$ ARG copies/d and $8.1 \pm 7.3 \times 10^{20}$ MGE copies/d; SI Table S13). The normalized copy number of ARGs and MGEs per cell increased from $0.1 \pm 0.1$ and $0.1 \pm 0$ upstream to $1.7 \pm 0.6$ and $1.6 \pm 0.6$ downstream, respectively. Detected numbers, concentrations, and normalized copy numbers for ARGs and MGEs were higher in both tributaries (M5 and Se1) than downstream in the Skudai river (S8) (SI Tables S13-S17).

Assessing Seasonal and Spatial Effects. Dimensionless Cohen's D effect sizes were calculated to inform the magnitude of spatial (up- vs downstream) and seasonal effects on water quality and AR levels. Reporting standardized effect sizes in concert with $P$ values allows one to better compare findings within and across studies. ${ }^{71}$ This is particularly important for LMIC settings where limited data availability hinders the identification of environmental AR "hot spots".

Seasonality only significantly influenced observed total antibiotic concentrations (paired $t$-test with $P<0.05$ and large Cohen's D effect size $>0.8$, SI Table S18). For all other parameters, season did not have any significant effects on concentration or mass loading data (Figure 5a, SI Table S18). Conversely, spatial differences (up- vs downstream) were significant for all parameters, and more apparent in mass loading data (Cohen's D range -13.9 for S16 rRNA to -6.8 for ESBL coliform, SI Table S19) versus concentration data 

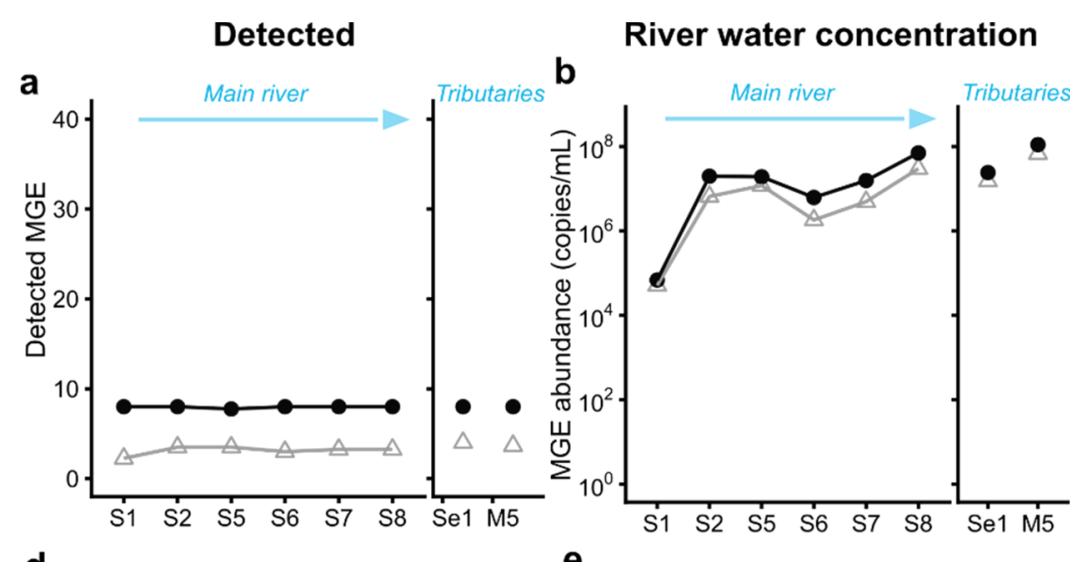

$$
\text { C }
$$

Normalized cell concentration
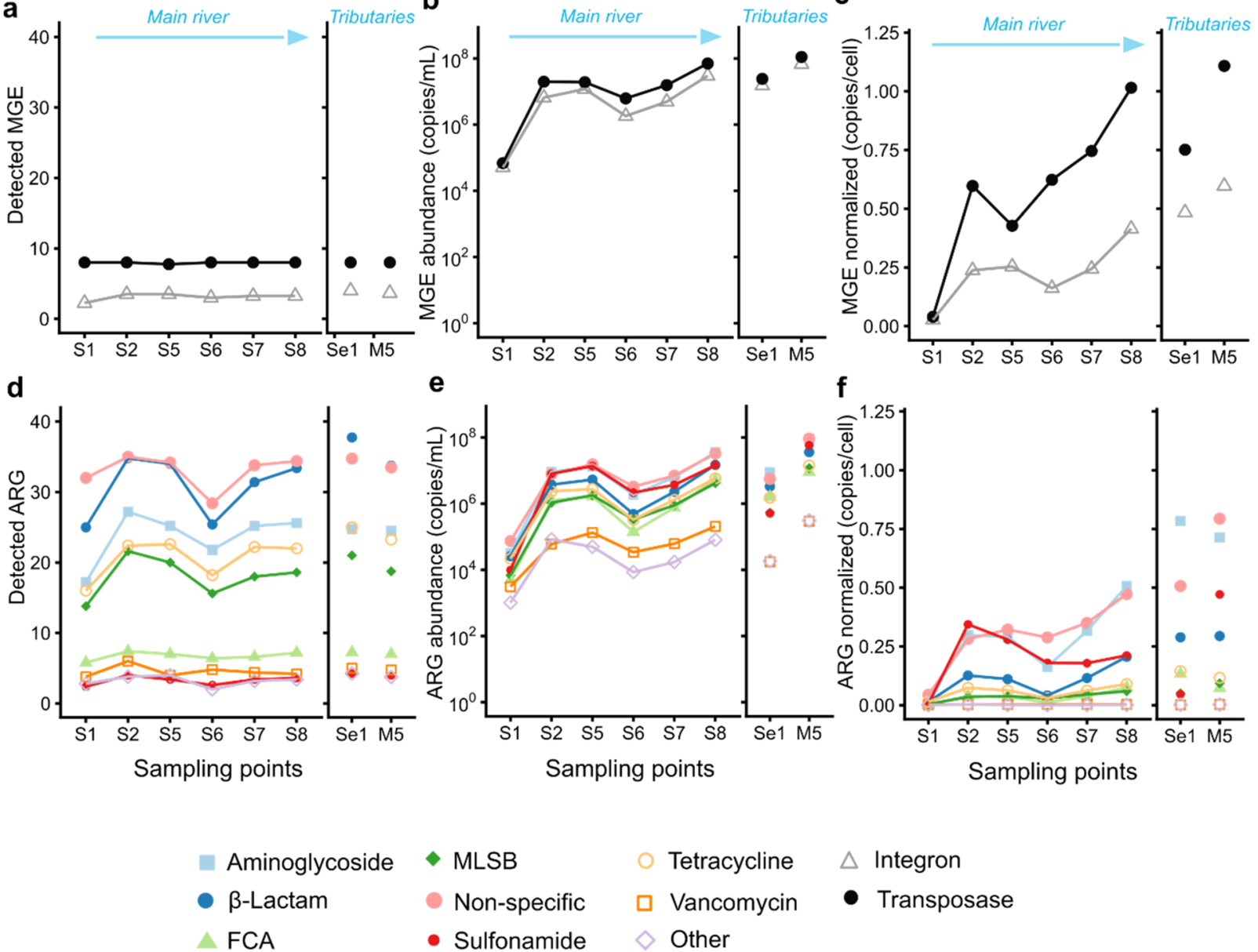

$\triangle$ Integron

- Transposase

Figure 3. Antibiotic-resistant gene (ARG) and mobile genetic element (MGE) detected (a, d), river water concentrations (b, e) and normalized cell concentration ( $c, f)$ measured with HT-qPCR per sampling point in the Skudai catchment. Mean data represented is based on four biological replicates for the main river (S1, S2, S5, S6, S7, S8) and on three biological replicates for the tributaries (Se1, M5). For standard deviations, see SI Tables S14-S17. FCA: fluoroquinolone, quinolone, florfenicol, chloramphenicol, and amphenicol ARGs. MLSB: macrolide-lincosamidestreptogramin B ARGs.

(Cohen's D range MGE -6.85 to -1.6 for CRB-0.5, SI Table S19). For concentrations, the largest Cohen's D effect sizes were observed for DO (Cohen's D 15.6), MGE, and ARG river water concentrations (Cohen's D -6.5 for ARG and -6.85 for MGE) (Figure 5b).

Defining a Surrogate Marker for Antibiotic Resistance. Spearman correlation analysis was performed between all monitored parameters to identify possible "easy-tomeasure" surrogates that associated with elevated AR in the catchment (Figure 6). For this, we focused on correlations between AR indicators (ESBL coliform, ESBL E. coli, total antibiotics, total ARGs, total MGEs, int1) and physicochemical water quality parameters (temperature, $\mathrm{pH}, \mathrm{DO}$, conductivity, $\left.\mathrm{NH}_{3}-\mathrm{N}, \mathrm{COD}, \mathrm{TN}, \mathrm{TP}\right)$. These standard water quality parameters also are included in the Malaysian river water quality monitoring program. ${ }^{72}$ Out of the physicochemical water quality parameters, $\mathrm{DO}$ and $\mathrm{NH}_{3}-\mathrm{N}$ correlated strongest with total ARGs, the sum of all ARG copy number concentrations in river water (Spearman's $\rho 0.81$ and 0.83 with $P<0.05$, respectively). Within the AR indicators, total ARGs correlated strongly with int 1 (Spearman's $\rho 0.98, P<0.05$ ) but less so with total antibiotics (Spearman's $\rho 0.7, P<0.05$ ). When comparing correlations between total ARGs and each
ARG class with total versus individual antibiotic concentrations, the strongest correlations always were between total ARGs and total antibiotics (SI Table S20). This was even true when comparing amoxicillin and ciprofloxacin with their ARG class, suggesting specific selection by individual antibiotics is not evident, even the detected antibiotics near their PNEC levels.

\section{DISCUSSION}

Comprehensive Environmental Antibiotic Resistance Monitoring. Discharge and mass loadings are rarely estimated in environmental AR monitoring studies. However, we show that both concentration and loading data provide valuable complementary information to understand processes occurring in a river catchment. In the Skudai, river health improved midstream at the semiurban sampling point S6 despite worse water quality conditions further up- and downstream. Considering the combination of lower pollutant concentrations and mass loadings, this was likely caused by a combination of reduced wastewater entering the river in this more agricultural reach (in comparison to more urbanized reaches up- and downstream) while simultaneously, rain and/or groundwater and/or cleaner tributaries (e.g., Senai) continued to dilute the river water with 


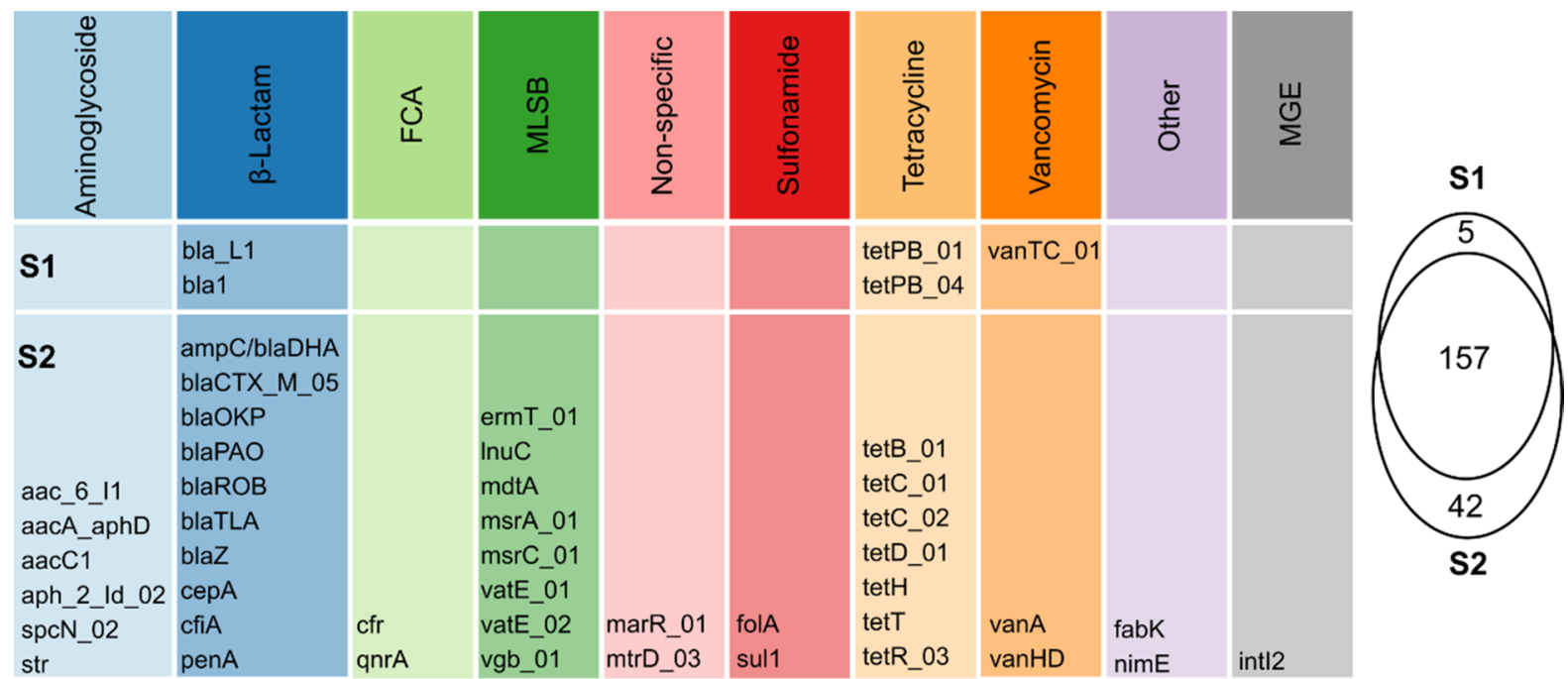

Figure 4. Differences in antibiotic-resistant gene (ARG) and mobile genetic element (MGE) detection between the most upstream rural sampling point S1 and the next, semiurban sampling point S2 on the Skudai. The Venn diagram indicates the number of ARGs and MGEs only detected at S1 (5), the number of shared ARGs and MGEs between S1 and S2 (157), and the number of ARGs and MGEs only detected at S2 (42). Data based on four biological replicates. FCA: fluoroquinolone, quinolone, florfenicol, chloramphenicol, and amphenicol ARGs. MLSB: macrolidelincosamide-streptogramin B ARGs.
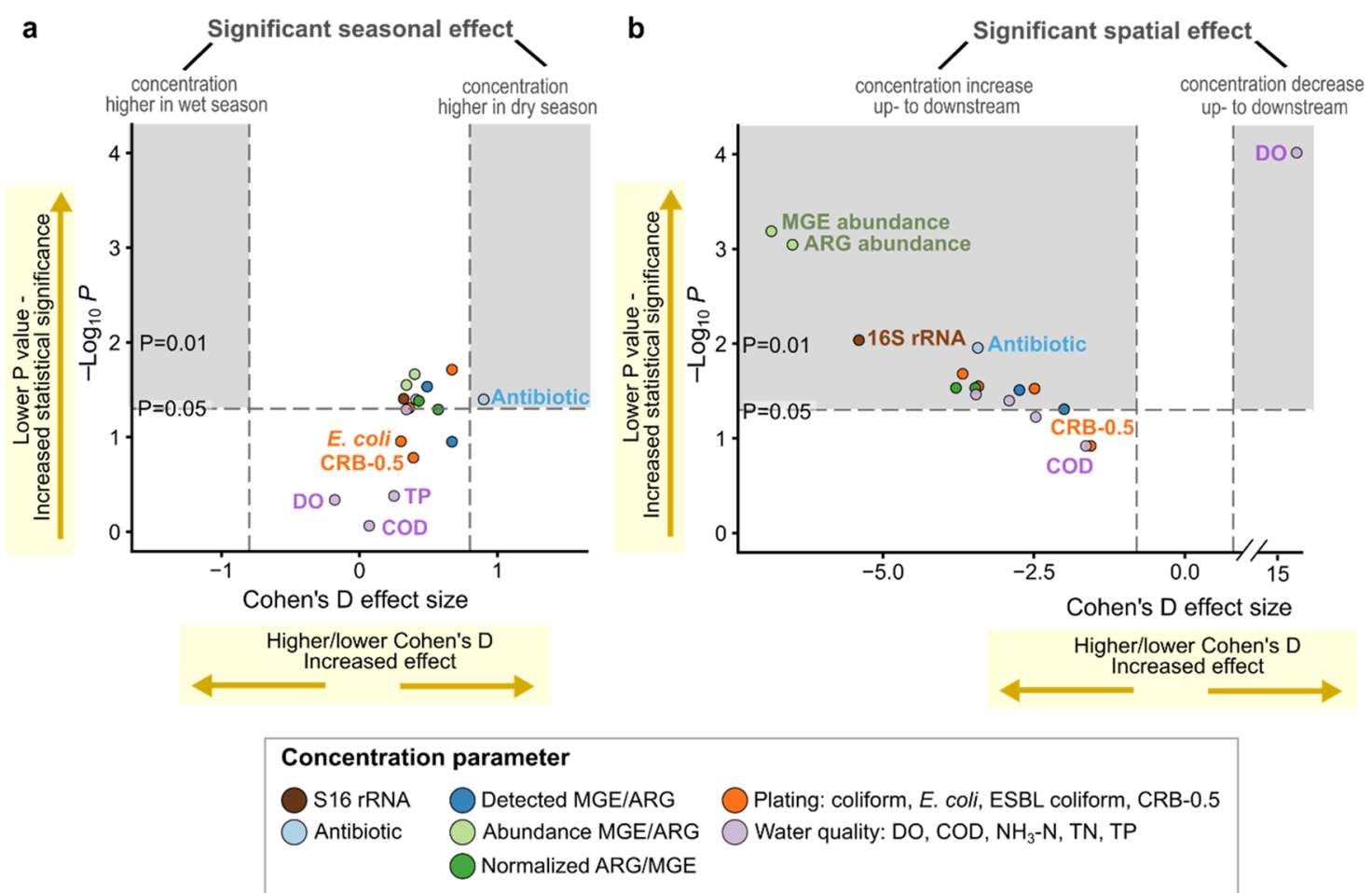

Figure 5. Comparing the effect of seasonality (a) and spatial variation between up- (S1) and downstream (S8) (b) for concentration parameters, based on statistical significance and Cohen's D effect size. Statistical comparisons performed with the paired $t$-test or Welch's $t$-test with Benjamini-Hochberg multiple testing correction. A high $-\log _{10} P$ value indicates high statistical significance with $-\log _{10} P(2)=P(0.01)$ and $-\log _{10} P(3)=P(0.001)$. A Cohen's D effect size over 0.8 or under -0.8 indicates a large seasonal or spatial effect on the parameter. Only selected parameters are labeled; for more details, see SI Tables S18 and S19. ARG: antibiotic-resistant genes. COD: chemical oxygen demand. CRB-0.5: carbapenem-resistant bacteria selected for with $0.5 \mu \mathrm{g} / \mathrm{mL}$ meropenem. ESBL: extended-spectrum $\beta$-lactamase. DO: dissolved oxygen. MGE: mobile genetic elements. $\mathrm{NH}_{3}-\mathrm{N}$ : ammonia. TC: total coliform. TN: total nitrogen. TP: total phosphorus.

pollutants degrading and/or settling to the sediment. ${ }^{73}$ More accurate methods exist to estimate flow than the applied float method. However, the easy and cost-effective application makes the float method particularly suitable for countries with limited resources. $^{74}$
Accounting for volumetric flow is particularly important for countries with dry and wet seasons. Comparing total antibiotic concentrations and mass loadings, we demonstrate that while antibiotic releases into the catchment likely do not vary across seasons for this catchment, reduced rainfall during the dry season resulted in increased river antibiotic concentrations and 


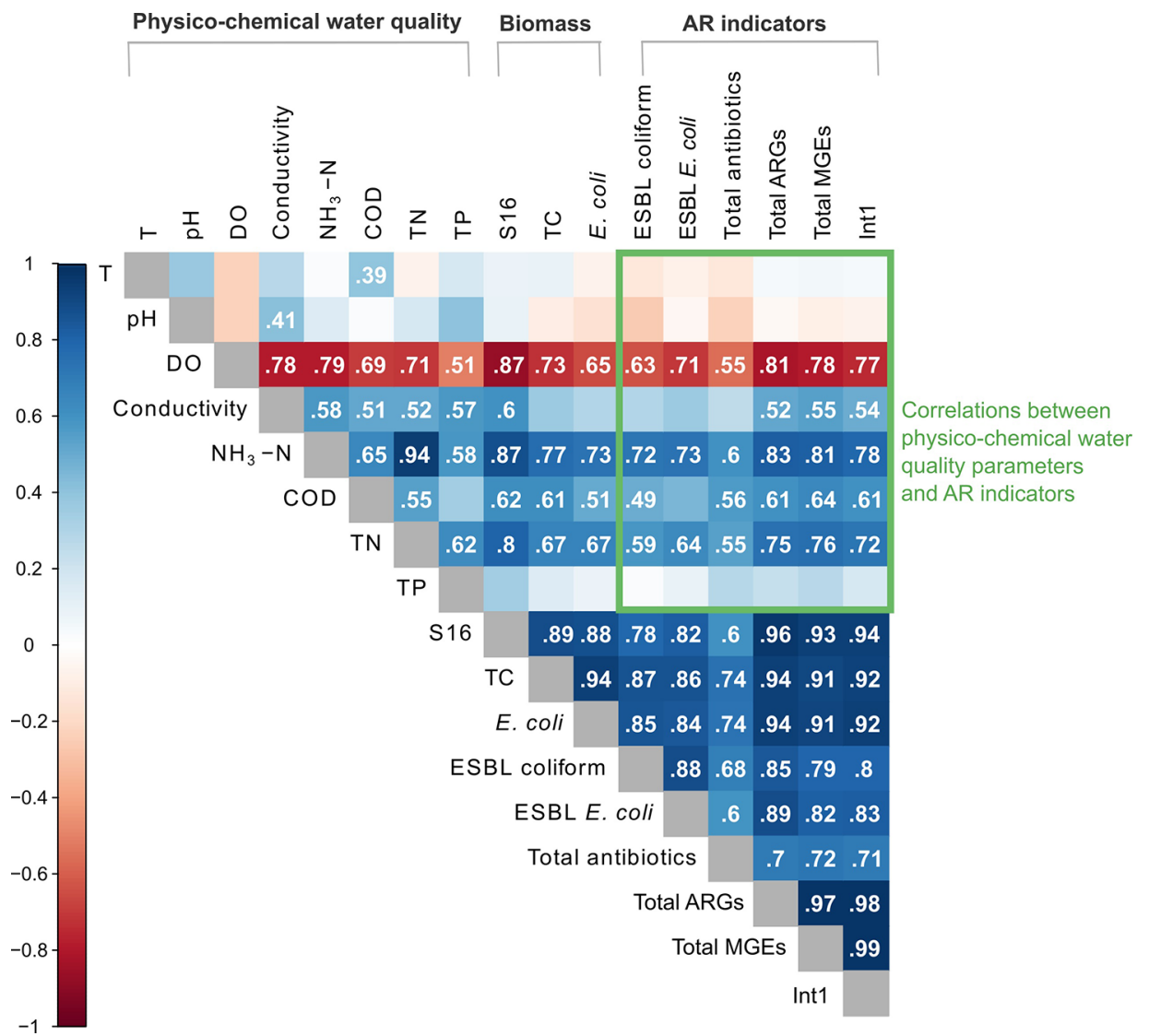

Figure 6. Spearman correlations between selected physicochemical water quality, biomass, and antibiotic resistance (AR) concentrations for the river catchment $(n=30)$. Correlation values only shown for $P<0.05$ with $P$ values corrected for multiple testing with the Benjamini-Hochberg approach. ARG: antibiotic-resistant genes. COD: chemical oxygen demand. DO: dissolved oxygen. MGE: mobile genetic elements. $\mathrm{NH}_{3}-\mathrm{N}$ : ammonia. S16: S16 rRNA gene. T: temperature. TC: total coliform. TN: total nitrogen. TP: total phosphorus.

consequently, increased exposure. Seasonality is expected to have a much larger effect on water quality/AR parameters in other SE Asian regions with more pronounced dry/wet seasons than here in southern peninsular Malaysia.

The highest antibiotic concentrations in the catchment based on both, maximum and mean, were recorded for amoxicillin, ciprofloxacin, and sulfamethoxazole. A 2014 study found amoxicillin to be the most prescribed antibiotic in Malaysia. ${ }^{75}$ Mean amoxicillin river concentrations were higher than previously recorded for European treated wastewater treatment plant effluents and surface waters. ${ }^{76-78}$ Sulfamethoxazole and ciprofloxacin concentrations were higher than previously recorded for Malaysian surface waters, ${ }^{7,80}$ but comparable to some other East and SE Asian surface water studies. ${ }^{81}$ There is limited knowledge on which environmental antibiotic concentrations select for resistant bacteria. ${ }^{51,82}$ In this study, only amoxicillin and ciprofloxacin exceeded the PNEC thresholds, ${ }^{51}$ particularly during the dry season.

Comparing the Skudai ARG concentrations to other ARG HT-qPCR studies based on the same primer sets and analytical methods (SI Figure S3), we found the upstream ARG levels to be comparable to previous findings in upstream Chinese river reaches $\left(10^{5}-10^{6}\right.$ ARG copies $\left./ \mathrm{mL}^{83,84}\right)$. Downstream Skudai ARG concentrations $\left(\sim 10^{8}\right.$ ARG copies $/ \mathrm{mL}$, this study and ref 83) were similar to wastewater treatment effluent ARG concentrations $\left(10^{7}-10^{9}\right.$ ARG copies $\left./ \mathrm{mL}\right)$ recorded in Spain and China but lower than influent ARG concentrations $\left(10^{9}-\right.$ $10^{10}$ ARG copies $/ \mathrm{mL}$ ) from those same studies. ${ }^{73,85}$ The detected number of ARGs upstream in the Skudai was higher than in any other of the reported upstream river water, upstream river sediment, lake, or soil samples. The number of detected ARGs downstream in this study also was the highest across all cited studies.

Movement from the rural (S1) to semiurban (S2) locale added over 40 additional genes, many associated with fecal matter and multidrug resistance, such as blaCTX-M and vanA. BlaCTX-M encodes for elevated resistance to $\beta$-lactam antibiotics. ${ }^{86}$ VanA is a plasmid borne gene that confers high resistance to vancomycin and is most commonly associated with Enterococcus faecium and Enterococcus faecalis. ${ }^{87}$ The S1 to S2 reach has limited wastewater treatment, which likely introduced these ARGs into the river, suggesting limited local wastewater treatment may be the dominant source of AR genes in this part of the river, which also was seen in an AR estuary study in southern Malaysian. ${ }^{33}$

Reporting Standardized Effect Sizes. Effect sizes are commonly applied in bioinformatics, medical drug trials, and meta-analysis. ${ }^{88}$ However, to the best of our knowledge, this is the first study to apply the principle of standardized effect sizes to $\mathrm{AR} /$ river water quality monitoring. While unstandardized effect size statistics such as mean differences are important, additional reporting of standardized, dimensionless effect sizes such as Cohen's D effect size allows one to more easily compare seasonal and spatial effects on various parameters. ${ }^{71}$ This is particularly crucial for understanding and comparing results from environmental AR monitoring studies where 
analysis costs are high, resulting in little available data, mostly existing for HICs. ${ }^{12}$ Routine reporting of effect sizes will encourage researchers to view their results in the context of previous studies and facilitate the incorporation of results into future meta-analysis. ${ }^{71}$ We support Nakawaga and Cuthill in their encouragement to report effect size statistics and their confidence intervals in all biological journals. ${ }^{71}$ Using volcano plots, we provide an easy way to visualize seasonal and spatial effects together with $P$ values to compare different water quality and AR parameters. For concentration data, we observed the largest statistically significant spatial effects (up vs downstream) for ARG, MGE, and DO concentrations. Spatial effects were even larger for all parameters based on their mass loadings than concentrations. This is not surprising when considering that the Skudai river increases in depth and particularly, width from $5 \mathrm{~m}$ at the most upstream sampling point to $75 \mathrm{~m}$ at the most downstream sampling point. For this study, we applied the Cohen's D threshold of over 0.8 or under -0.8 to define a large effect size as originally proposed by Cohen for behavioral studies. ${ }^{89}$ However, depending on the study design, this threshold can be adapted.

Surrogate Marker for Predicting Antibiotic Resistance. River water in more urban areas of the Skudai catchment are characterized by higher $\mathrm{NH}_{3}-\mathrm{N}$ and lower DO levels, both indicators of wastewater pollution. ${ }^{90}$ When sewage enters a river, the organic matter- and nitrogencontaining components are oxidized, decreasing DO levels. ${ }^{91}$ This process has been known for many years and is mathematically described by DO sag curves. ${ }^{92}$ Based on our data and local water quality thresholds, the Skudai catchment is classified in the slightly polluted to polluted range, which aligns with the Malaysian DOE classification. ${ }^{93}$ Our DO and $\mathrm{NH}_{3}-\mathrm{N}$ data aligns well with the long-term national Malaysian data set (Figure $1 \mathrm{~b}, \mathrm{c}$ ), suggesting that our correlations between these parameters and AR markers might be used to extend existing Malaysian data sets to AR prediction, in theory suggesting places of elevated $A R$, using modeling, where no current $A R$ data exists.

Modeling represents an efficient, cost-effective tool for LMICs to identify AR hot spots in rivers and propose engineering and/or social interventions. However, while many river water quality models exist, ${ }^{94-96}$ no standardized, hydrological model yet includes an AR component. Conversely, many LMICs, including Malaysia, ${ }^{93}$ operate longstanding national river monitoring programmes, but these do not capture AR either. Here, we investigated which easy-tomeasure water quality parameter included in well-established river water quality models and captured in the Malaysian river water quality monitoring programme could act as a surrogate to predict AR levels in rivers with no/limited AR background data.

For the Skudai catchment, we found $\mathrm{DO}$ and $\mathrm{NH}_{3}-\mathrm{N}$ exhibit the strongest correlations with high total ARG concentrations. This does not mean that low DO or high $\mathrm{NH}_{3}-\mathrm{N}$ themselves directly causes higher ARG levels (or vice versa), although horizontal gene transfer (HGT) frequency can be higher under low-oxygen conditions, ${ }^{97}$ suggesting that lower DO may increase local ARG HGT. In this catchment, lower DO and higher $\mathrm{NH}_{3}-\mathrm{N}$ are likely associated with insufficiently treated sewage entering the river, which is probably also the major route for ARGs entering the river.

Given the above, DO is well suited as a surrogate for AR as it can easily be measured with a hand-held probe, relative differences often mirror sewage inputs, and DO potentially impacts in situ HGT frequency. DO is also one of the most commonly modeled indicators of stream, river, and lake health with a vast array of models available. ${ }^{98}$ Consequently, we propose that for this catchment, DO concentrations are a useful surrogate to understand previous AR levels and model future AR levels. Future work should evaluate the applicability of this surrogate for other catchments in Malaysia and SE Asia. However, for such surrogates to have the greatest value, they should be coupled with other predictive AR approaches that do not heavily rely on directly monitored data, such as genomic and other modeling tools for AR bacteria. ${ }^{99-101}$

Interestingly, within the AR indicators, total antibiotic concentrations exhibited the lowest correlations with other AR parameters. The weaker correlation of total antibiotics with the other AR parameters might be due to the fact that many antibiotics quickly degrade in the environment while some ARGs and ARBs persist for longer. ${ }^{102}$ However, even in the Skudai river that has relatively high antibiotic levels, any selective effect of antibiotics is probably minor (Figure 2) compared with the greater load of ARGs entering the river through less treated wastewater (Figure 3). This is best exemplified by the many "new" ARGs entering the river between S1 and S2 (Figure 4), which dwarfs any effect of antibiotics themselves. This does not mean low levels of antibiotics are incapable of influencing ARG selection in aquatic systems, ${ }^{103}$ but data here suggest untreated sewage inputs have a much greater impact than in situ antibiotics on AR in catchments like the Skudai.

Taken together, this study shows that simple water quality markers, like $\mathrm{DO}$ and $\mathrm{NH}_{3}-\mathrm{N}$, can be valuable surrogates for local stakeholders to identify AR hot spots in rivers to target interventions. This does not mean that they are universally applicable, such as near major nonsewage organic waste inputs. However, DO and $\mathrm{NH}_{3}-\mathrm{N}$ clearly mirror sewage, which often dominates ARG and AR bacteria inputs, especially in LMIC rivers. $\mathrm{DO}$ and $\mathrm{NH}_{3}-\mathrm{N}$ also are inexpensive to measure and already exist in current monitoring programmes. Therefore, we propose $\mathrm{DO}$ and $\mathrm{NH}_{3}-\mathrm{N}$ as the "first point of call" surrogates for AR in rivers. They clearly can be coupled with parameters such as ESBL E. coli for environmental AR monitoring, which the WHO is already using to monitor AR across environments (Tricycle project ${ }^{104}$ ). However, DO and $\mathrm{NH}_{3}-\mathrm{N}$ are more amenable to water quality modeling, which might ultimately be the most affordable way of identifying AR "hot spots" in places with limited existing data.

\section{ASSOCIATED CONTENT}

\section{Supporting Information}

The Supporting Information is available free of charge at https://pubs.acs.org/doi/10.1021/acs.est.1c00939.

Methodological details on the antibiotics analysis; map of Skudai catchment with sampling points (Figure S1); total coliform, ESBL coliform, and carbapenem-resistant bacterial concentrations and mass loadings in the river catchment (Figure S2); comparison of HT-qPCR ARG detection and concentrations across different studies (Figure S3); sampling point coordinates (Table S1); modified water quality classes in Malaysia (Table S2); Malaysian Department of Environment water quality for the Skudai catchment (Table S3); monitored antibiotics from the Skudai river catchment across the four 
sampling campaigns (Table S4); relative SPE recovery, method detection limit (MDL), and method quantification limit (MQL) for antibiotics in surface water (Table S5); ARG and MGE primer list for the HT-qPCR (Table S6); Box-Cox transformations prior statistical analysis (Table S7); monitored physical parameters per sampling point across the four sampling campaigns (Table S8); monitored chemical parameters per sampling point across the four campaigns (Table S9); chemical mass loadings at each sampling point across the four campaigns (Table S10); coliform concentrations at each sampling point in CFUs in river water samples (Table S11); coliform mass loadings at each sampling point in CFUs per day (Table S12); summary of ARGs and MGEs in river water samples (Table S13); detected ARGs per antibiotic class in river water samples (Table S14); ARG concentration for each antibiotic class in river water samples (Table S15); normalized ARGs per cell in river water samples (Table S16); MGE concentrations in river water samples (Table S17); paired $t$-tests and Cohen's D effect sizes comparing seasonal mass loadings, concentrations, and detected numbers for water quality and antibiotic-resistant parameters (Table S18); Welch's $t$-test and Cohen's D effect sizes comparing spatial mass loadings, concentrations, and detected numbers for water quality and antibiotic-resistant parameters (Table S19); Spearman correlations between river water concentrations of total antibiotics, amoxicillin, ciprofloxacin, total ARGs, and ARGs reported by antibiotic class (Table S20) (PDF)

\section{AUTHOR INFORMATION}

\section{Corresponding Author}

David W. Graham - School of Engineering, Newcastle University, NE1 7RU Newcastle upon Tyne, United Kingdom; 이이이.org/0000-0002-9753-496X; Email: david.graham@newcastle.ac.uk

\section{Authors}

Amelie Ott - School of Engineering, Newcastle University, NE1 7RU Newcastle upon Tyne, United Kingdom

Greg O'Donnell - School of Engineering, Newcastle University, NE1 7RU Newcastle upon Tyne, United Kingdom

Ngoc Han Tran - Department of Civil and Environmental Engineering, National University of Singapore, 117576, Singapore

Mohd Ridza Mohd Haniffah - Universiti Teknologi Malaysia, 81310 Skudai, Johor, Malaysia

Jian-Qiang Su - Chinese Academy of Science, Institute of Urban Environment, 1799 Xiamen, China; (1) orcid.org/ 0000-0003-1875-249X

Andrew M. Zealand - School of Engineering, Newcastle University, NE1 7RU Newcastle upon Tyne, United Kingdom

Karina Yew-Hoong Gin - Department of Civil and Environmental Engineering, National University of Singapore, 117576, Singapore; ○ orcid.org/0000-0002-1266-9276

Michaela L. Goodson - Newcastle University Malaysia, 79200 Iskandar Puteri, Johor, Malaysia

Yong-Guan Zhu - Chinese Academy of Science, Institute of Urban Environment, 1799 Xiamen, China

Complete contact information is available at: https://pubs.acs.org/10.1021/acs.est.1c00939

\section{Funding}

This work was funded by the Newcastle University SAgE Singapore Scholarships programme, a British Council Newton Fund Institutional Links grant (331945729), a UK EPSRC Impact Acceleration Award (EP/K503885/1), and the UK Research and Innovation's Global Challenges Research Fund (ES/S008179/1). HT-qPCR analysis was funded by the Key Collaborative Research Program of the Alliance of International Science Organizations (ANSO-CR-KP-2020-03).

\section{Notes}

The authors declare no competing financial interest.

\section{ACKNOWLEDGMENTS}

The authors acknowledge the support from research staff at NUMed, including Jia Yee Ho, Sylvia Sue Xian Liew, Muhammad Noor Hazwan Jusoh, and Mardhiah Zainal Abidin. They also thank Mui-Choo Jong and Marcos Quintela-Baluja from Newcastle University for their expert feedback and assistance. They thank Xinyuan Zhou at the Institute of Urban Environment, Chinese Academy of Science, for assistance on the HT-qPCR assay as well as the Malaysian Department of Environment for providing background water quality data.

\section{REFERENCES}

(1) O'Neill, J. Tackling Drug-Resistant Infections Globally: Final Report and Recommendations; HM Government and Welcome Trust: London, United Kingdom, 2016; p 84.

(2) Michael, C. A.; Dominey-Howes, D.; Labbate, M. The Antimicrobial Resistance Crisis: Causes, Consequences, and Management. Front. Public Health 2014, 2, No. 145.

(3) Abushaheen, M. A.; Muzaheed Fatani, A. J.; Alosaimi, M.; Mansy, W.; George, M.; Acharya, S.; Rathod, S.; Divakar, D. D.; Jhugroo, C.; Vellappally, S.; Khan, A. A.; Shaik, J.; Jhugroo, P. Antimicrobial Resistance, Mechanisms and Its Clinical Significance. Dis.-Mon. 2020, 66, No. 100971.

(4) Bürgmann, H.; Frigon, D.; Gaze, W. H.; Manaia, C. M.; Pruden, A.; Singer, A. C.; Smets, B. F.; Zhang, T. Water and Sanitation: An Essential Battlefront in the War on Antimicrobial Resistance. FEMS Microbiol. Ecol. 2018, 94, No. fiy101.

(5) Sobsey, M. A.; Andremont, A.; Ashbolt, N. J. et al. Antimicrobial Resistance: An Emerging Water, Sanitation and Hygiene Issue. Briefing Note WHO/FWC/WSH/14.07; World Health Organization, 2014.

(6) Davis, B. C.; Riquelme, M. V.; Ramirez-Toro, G.; Bandaragoda, C.; Garner, E.; Rhoads, W. J.; Vikesland, P.; Pruden, A. Demonstrating an Integrated Antibiotic Resistance Gene Surveillance Approach in Puerto Rican Watersheds Post-Hurricane Maria. Environ. Sci. Technol. 2020, 54, 15108-15119.

(7) Huijbers, P. M. C.; Flach, C.-F.; Larsson, D. G. J. A Conceptual Framework for the Environmental Surveillance of Antibiotics and Antibiotic Resistance. Environ. Int. 2019, 130, No. 104880.

(8) Dunachie, S. J.; Day, N. P.; Dolecek, C. The Challenges of Estimating the Human Global Burden of Disease of Antimicrobial Resistant Bacteria. Curr. Opin. Microbiol. 2020, 57, 95-101.

(9) Nuzzo, R. Statistical Errors. Nature 2016, 47-74.

(10) Sullivan, G. M.; Feinn, R. Using Effect Size-or Why the $P$ Value Is Not Enough. J. Grad. Med. Educ. 2012, 4, 279-282.

(11) World Health Organization, Unicef. Progress on Drinking Water, Sanitation and Hygiene: 2017 Update and SDG Baselines; World Health Organization, 2017; p 114.

(12) Vikesland, P.; Garner, E.; Gupta, S.; Kang, S.; Maile-Moskowitz, A.; Zhu, N. Differential Drivers of Antimicrobial Resistance across the World. Acc. Chem. Res. 2019, 52, 916-924.

(13) Klein, E. Y.; Van Boeckel, T. P.; Martinez, E. M.; Pant, S.; Gandra, S.; Levin, S. A.; Goossens, H.; Laxminarayan, R. Global Increase and Geographic Convergence in Antibiotic Consumption 
between 2000 and 2015. Proc. Natl. Acad. Sci. U.S.A. 2018, 115, E3463-E3470.

(14) Coker, R. J.; Hunter, B. M.; Rudge, J. W.; Liverani, M.; Hanvoravongchai, P. Emerging Infectious Diseases in Southeast Asia: Regional Challenges to Control. Lancet 2011, 377, 599-609.

(15) Walther, B. A.; Boëte, C.; Binot, A.; By, Y.; Cappelle, J.; Carrique-Mas, J.; Chou, M.; Furey, N.; Kim, S.; Lajaunie, C.; Lek, S.; Méral, P.; Neang, M.; Tan, B. H.; Walton, C.; Morand, S. Biodiversity and Health: Lessons and Recommendations from an Interdisciplinary Conference to Advise Southeast Asian Research, Society and Policy. Infect., Genet. Evol. 2016, 40, 29-46.

(16) Zellweger, M.; Carrique-mas, J.; Limmathurotsakul, D.; Day, N. P. J.; Thwaites, G. E. A Current Perspective on Antimicrobial Resistance in Southeast Asia. J. Antimicrob. Chemother. 2017, 72, 2963-2972.

(17) Hu, Y. J.; Ogyu, A.; Cowling, B. J.; Fukudaa, K.; Panga, H. Available Evidence of Antibiotic Resistance from Extended-Spectrum B-Lactamase-Producing Enterobacteriaceae in Paediatric Patients in 20 Countries: A Systematic Review and Meta-Analysis. Bull. W. H. O. 2019, 97, 486-501B.

(18) Malchione, M. D.; Torres, L. M.; Hartley, D. M.; Koch, M.; Goodman, J. L. Carbapenem and Colistin Resistance in Enterobacteriaceae in Southeast Asia: Review and Mapping of Emerging and Overlapping Challenges. Int. J. Antimicrob. Agents 2019, 54, 381399.

(19) World Bank. The World Bank in Malaysia. https://www. worldbank.org/en/country/malaysia/overview (accessed Dec 10, 2020).

(20) Ab Rahman, N.; Teng, C. L.; Sivasampu, S. Antibiotic Prescribing in Public and Private Practice: A Cross-Sectional Study in Primary Care Clinics in Malaysia. BMC Infect. Dis. 2016, 16, No. 208.

(21) Ministry of Health Malaysia. Malaysian Action Plan on Antimicrobial Resistance (MyAP-AMR) 2017-2021; Ministry of Agriculture \& Agro-Based Industry Malaysia, 2017.

(22) National Antibiotic Resistance Surveillance Report; Antibiotic Resistance Surveillance Reference Laboratory, 2019.

(23) Kakkar, M.; Chatterjee, P.; Chauhan, A. S.; Grace, D.; Lindahl, J.; Beeche, A.; Jing, F.; Chotinan, S. Antimicrobial Resistance in South East Asia: Time to Ask the Right Questions. Global Health Action 2018, 11, No. 1483637.

(24) Birkegård, A. C.; Halasa, T.; Toft, N.; Folkesson, A.; Græsbøll, K. Send More Data: A Systematic Review of Mathematical Models of Antimicrobial Resistance. Antimicrob. Resist. Infect. Control 2018, 7, No. 117.

(25) Niewiadomska, A. M.; Jayabalasingham, B.; Seidman, J. C.; Willem, L.; Grenfell, B.; Spiro, D.; Viboud, C. Population-Level Mathematical Modeling of Antimicrobial Resistance: A Systematic Review. BMC Med. 2019, 17, No. 81.

(26) Wang, Q.; Li, S.; Jia, P.; Qi, C.; Ding, F. A Review of Surface Water Quality Models. Sci. World J. 2013, 2013, No. 231768.

(27) Hellweger, F. L. Simple Model of Tetracycline Antibiotic Resistance in Aquatic Environment: Accounting for Metal Coselection. J. Environ. Eng. 2013, 139, 913-921.

(28) Gothwal, R.; Thatikonda, S. Mathematical Model for the Transport of Fluoroquinolone and Its Resistant Bacteria in Aquatic Environment. Environ. Sci. Pollut. Res. 2017, 25, 20439-20452.

(29) Lawrence, B.; Mummert, A.; Somerville, C. A Model of the Number of Antibiotic Resistant Bacteria in Rivers. 2010, arXiv:1007.1383. arXiv.org e-Print archive. http://arxiv.org/abs/ 1007.1383.

(30) Bello, A. D.; Hashim, N.; Mohd Haniffah, M. Predicting Impact of Climate Change on Water Temperature and Dissolved Oxygen in Tropical Rivers. Climate 2017, 5, No. 58.

(31) Bello, A. A.; Haniffah, M. R. M.; Hanapi, M. N.; Usman, A. B. Identification of Critical Source Areas under Present and Projected Land Use for Effective Management of Diffuse Pollutants in an Urbanized Watershed. Int. J. River Basin Manage. 2019, 17, 171-184.
(32) Review of the National Water Resources Study (2000-2050) and Formulation of National Water Resources Policy-Final Report; Ranhill Consulting Sdn Bhd, 2011.

(33) Ho, J. Y.; Jong, M.-C.; Acharya, K.; Liew, S. S. X.; Smith, D. R.; Noor, Z. Z.; Goodson, M. L.; Werner, D.; Graham, D. W.; Eswaran, J. Multidrug-Resistant Bacteria and Microbial Communities in a River Estuary with Fragmented Suburban Waste Management. J. Hazard. Mater. 2020, 405, No. 124687.

(34) Bello, A. D. Modelling the Impacts of Land-Use and Climate Change in Skudai River Watershed. Ph.D. Thesis, UTM, 2018.

(35) UNICEF. Progress on Household Drinking Water, Sanitation and Hygiene 2000-2017. Special Focus on Inequalities; WHO, 2019.

(36) IWK. Sewage. https://www.iwk.com.my/do-you-know/sewagetreatment-methods (accessed Aug 30, 2017).

(37) Wong, C. L.; Venneker, R.; Uhlenbrook, S.; Jamil, A. B. M.; Zhou, Y. Variability of Rainfall in Peninsular Malaysia. Hydrol. Earth Syst. Sci. Discuss. 2009, 6, 5471-5503.

(38) WEPA. Water Environmental Management in Asia 2015; WEPA, 2015.

(39) Michaud, J. P.; Wierenga, M. Estimating Discharge and Stream Flows. A Guide for Sand and Gravel Operators; Ecology Publication, 2005; Vol. 70.

(40) Hydromatch. Flow Estimation for Streams and Small Rivers; Hydromatch Ltd, 2014.

(41) Hach. Nitrogen, Ammonia-Method 10031; Hach Company: USA, 2015.

(42) Hach. Chemical Oxygen Demand-Method 8000; Hach Company: USA, 2014.

(43) Hach. Phosphorus-Method 8190; Hach Company: USA, 2014.

(44) Hach. Nitrogen, Total-Method 10071; Hach Company: USA, 2014.

(45) Huang, Y. F.; Ang, S. Y.; Lee, K. M.; Lee, T. S. Quality of Water Resources in Malaysia. In Research and Practices in Water Quality; IntechOpen, 2015.

(46) Sigma Aldrich. ESBL ChromoSelect Agar Supplement, Product Information 61471; ESBL agar, 2013.

(47) Hands, C. Relationships between Zinc and Meropenem Resistance in the Natural Environment and Experimental Bioreactors; Newcastle University, 2016.

(48) Clinical and Laboratory Standard Institute. Performance Standards for Antimicrobial Susceptibility Testing, CLSI Supplement M100; 31st ed.; CLSI, 2021.

(49) Maheux, A. F.; Bouchard, S.; Bérubé, È.; Bergeron, M. G. Comparison of MI, Chromocult Coliform, and Compass CC Chromogenic Culture-Based Methods to Detect Escherichia coli and Total Coliforms in Water Using 16S RRNA Sequencing for Colony Identification. J. Water Health 2017, 15, 353-359.

(50) Breed, R. S.; Dotterrer, W. D. The Number of Colonies Allowable on Satisfactory Agar Plates. J. Bacteriol. 1916, 1, 321-331.

(51) Bengtsson-Palme, J.; Larsson, D. G. J. Concentrations of Antibiotics Predicted to Select for Resistant Bacteria: Proposed Limits for Environmental Regulation. Environ. Int. 2016, 86, 140-149.

(52) Zhu, Y. G.; Zhao, Y.; Li, B.; Huang, C. L.; Zhang, S. Y.; Yu, S.; Chen, Y. S.; Zhang, T.; Gillings, M. R.; Su, J. Q. Continental-Scale Pollution of Estuaries with Antibiotic Resistance Genes. Nat. Microbiol. 2017, 2, No. 16270.

(53) Zhu, Y. G.; Johnson, T. A.; Su, J. Q.; Qiao, M.; Guo, G. X.; Stedtfeld, R. D.; Hashsham, S. A.; Tiedje, J. M. Diverse and Abundant Antibiotic Resistance Genes in Chinese Swine Farms. Proc. Natl. Acad. Sci. U.S.A. 2013, 110, 3435-3440.

(54) Klappenbach, J. A. Rrndb: The Ribosomal RNA Operon Copy Number Database. Nucleic Acids Res. 2001, 29, 181-184.

(55) R Core Team. R: A Language and Environment for Statistical Computing; R Foundation for Statistical Computing: Vienna, Austria, 2020.

(56) Wickham, H. Ggplot2: Elegant Graphics for Data Analysis; Springer-Verlag: New York, 2016.

(57) Inkscape. Inkscape Project, 2017. https://inkscape.org/. 
(58) Desktop, E. A. ESRI ArcGIS; Environmental Systems Research Institute: Redlands, CA, 2018.

(59) Attal, M. Structural Analysis of Rocks and Regions 2017. Topogr. Anal. 2017, 1-22.

(60) Antweiler, R. C. Evaluation of Statistical Treatments of LeftCensored Environmental Data Using Coincident Uncensored Data Sets. II. Group Comparisons. Environ. Sci. Technol. 2015, 49, 1343913446 .

(61) Cohen, J. A Power Primer. Psychol. Bull. 1992, 112, No. 155.

(62) Kassambara, A.T-test Effect Size Using Cohen's D Measure. https://www.datanovia.com/en/lessons/t-test-effect-size-usingcohens-d-measure/\#cohens-d-for-welch-test (accessed Dec 2, 2020).

(63) Delacre, M.; Lakens, D.; Leys, C. Why Psychologists Should by Default Use Welch's t-Test Instead of Student's t-Test. Int. Rev. Soc. Psychol. 2017, 30, 92-101.

(64) Benjamini, Y.; Hochberg, Y. Controlling the False Discovery Rate: A Practical and Powerful Approach to Multiple Testing. J. R. Stat. Soc., Ser. B 1995, 57, 289-300.

(65) Torchiano, M. effsize: Efficient Effect Size Computation, R package version $0.7,2020$.

(66) Box, G. E. P.; Cox, D. R. An Analysis of Transformations. J. R. Stat. Soc., Ser. B 1964, 26, 211-243.

(67) Riplley, B.; Venables, B.; Bates, D. M.; Firth, D.; Hornik, K.; Gebhardt, A. Package "MASS". Support Functions and Datasets for Venables and Ripley's MASS, 2018. http://www.r-project.org.

(68) Blighe, K.; Rana, S.; Lewis, M. EnhancedVolcano: PublicationReady Volcano Plots with Enhanced Colouring and Labeling, R package version 1.0, 2020.

(69) Revelle, W. Psych: Procedures for Personality and Psychological Research; Northwestern University: Evanston, Illinois, USA, 2019.

(70) Wei, T.; Simko, V. R Package "Corrplot": Visualization of a Correlation Matrix, R package version 0.84, 2017.

(71) Nakagawa, S.; Cuthill, I. C. Effect Size, Confidence Interval and Statistical Significance: A Practical Guide for Biologists. Biol. Rev. 2007, 82, 591-605.

(72) WEPA. Outlook on Water Environmental Management in Asia, 2018. www.wepa-db.net/pdf/1203outlook/01.pdf.

(73) Quintela-Baluja, M.; Abouelnaga, M.; Romalde, J.; Su, J.-Q.; Yu, Y.; Gomez, M.; Smets, B.; Zhu, Y.-G.; Graham, D. Spatial Ecology of Wastewater Networks Define the Antibiotic Resistance Genes Found in Downstream Receiving Waters. Water Res. 2019, 162, 347-357.

(74) Dobriyal, P.; Badola, R.; Tuboi, C.; Hussain, S. A. A Review of Methods for Monitoring Streamflow for Sustainable Water Resource Management. Appl. Water Sci. 2017, 7, 2617-2628.

(75) Sivasampu, S.; Yasmin Farhana, A.; Ong, S.; Goh, P.; Noor Hisham, A. National Medical Care Statistics Primary Care 2014; National Clinical Research Centre: Kuala Lumpur, 2016.

(76) Andreozzi, R.; Caprio, V.; Ciniglia, C.; De Champdoré, M.; Lo Giudice, R.; Marotta, R.; Zuccato, E. Antibiotics in the Environment: Occurrence in Italian STPs, Fate, and Preliminary Assessment on Algal Toxicity of Amoxicillin. Environ. Sci. Technol. 2004, 38, 68326838.

(77) Castiglioni, S.; Bagnati, R.; Calamari, D.; Fanelli, R.; Zuccato, E. A Multiresidue Analytical Method Using Solid-Phase Extraction and High-Pressure Liquid Chromatography Tandem Mass Spectrometry to Measure Pharmaceuticals of Different Therapeutic Classes in Urban Wastewaters. J. Chromatogr. A 2005, 1092, 206-215.

(78) Kasprzyk-Hordern, B.; Dinsdale, R. M.; Guwy, A. J. MultiResidue Method for the Determination of Basic/Neutral Pharmaceuticals and Illicit Drugs in Surface Water by Solid-Phase Extraction and Ultra Performance Liquid Chromatography-Positive Electrospray Ionisation Tandem Mass Spectrometry. J. Chromatogr. A 2007, $1161,132-145$.

(79) Low, K.; Chai, L.; Lee, C.; Zhang, G.; Zhang, R.; Vahab, V.; Bong, C. Prevalence and Risk Assessment of Antibiotics in Riverine Estuarine Waters of Larut and Sangga Besar River, Perak. J. Oceanol. Limnol. 2020, 39, 122-134.

(80) Shimizu, A.; Takada, H.; Koike, T.; Takeshita, A.; Saha, M.; Rinawati; Nakada, N.; Murata, A.; Suzuki, T.; Suzuki, S.; Chiem, N.
H.; Tuyen, B. C.; Viet, P. H.; Siringan, M. A.; Kwan, C.; Zakaria, M. P.; Reungsang, A. Ubiquitous Occurrence of Sulfonamides in Tropical Asian Waters. Sci. Total Environ. 2013, 452-453, 108-115.

(81) Anh, H. Q.; Le, T. P. Q.; Da Le, N.; Lu, X. X.; Duong, T. T.; Garnier, J.; Rochelle-Newall, E.; Zhang, S.; Oh, N.-H.; Oeurng, C.; Ekkawatpanit, C.; Nguyen, T. D.; Nguyen, Q. T.; Nguyen, T. D.; Nguyen, T. N.; Tran, T. L.; Kunisue, T.; Tanoue, R.; Takahashi, S.; Minh, T. B.; Le, H. T.; Pham, T. N. M.; Nguyen, T. A. H. Antibiotics in Surface Water of East and Southeast Asian Countries: A Focused Review on Contamination Status, Pollution Sources, Potential Risks, and Future Perspectives. Sci. Total Environ. 2020, 764, No. 142865.

(82) Tell, J.; Caldwell, D. J.; Häner, A.; Hellstern, J.; Hoeger, B.; Journel, R.; Mastrocco, F.; Ryan, J. J.; Snape, J.; Straub, J. O.; Vestel, J. Science-Based Targets for Antibiotics in Receiving Waters from Pharmaceutical Manufacturing Operations. Integr. Environ. Assess. Manage. 2019, 15, 312-319.

(83) Peng, F.; Guo, Y.; Isabwe, A.; Chen, H.; Wang, Y.; Zhang, Y.; Zhu, Z.; Yang, J. Urbanization Drives Riverine Bacterial Antibiotic Resistome More than Taxonomic Community at Watershed Scale. Environ. Int. 2020, 137, No. 105524.

(84) Zheng, J.; Zhou, Z.; Wei, Y.; Chen, T.; Feng, W.; Chen, H. High-Throughput Profiling of Seasonal Variations of Antibiotic Resistance Gene Transport in a Peri-Urban River. Environ. Int. 2018, 114, 87-94.

(85) An, X. L.; Su, J. Q.; Li, B.; Ouyang, W. Y.; Zhao, Y.; Chen, Q. L.; Cui, L.; Chen, H.; Gillings, M. R.; Zhang, T.; Zhu, Y. G. Tracking Antibiotic Resistome during Wastewater Treatment Using High Throughput Quantitative PCR. Environ. Int. 2018, 117, 146-153.

(86) Ramadan, A. A.; Abdelaziz, N. A.; Amin, M. A.; Aziz, R. K. Novel BlaCTX-M Variants and Genotype-Phenotype Correlations among Clinical Isolates of Extended Spectrum Beta LactamaseProducing Escherichia coli. Sci. Rep. 2019, 9, No. 4224.

(87) O’Driscoll, T.; Crank, C. W. Vancomycin-Resistant Enterococcal Infections: Epidemiology, Clinical Manifestations, and Optimal Management. Infect. Drug Resist. 2015, 8, No. 217.

(88) Debelius, J.; Song, S. J.; Vazquez-Baeza, Y.; Xu, Z. Z.; Gonzalez, A.; Knight, R. Tiny Microbes, Enormous Impacts: What Matters in Gut Microbiome Studies? Genome Biol. 2016, 17, No. 217.

(89) Cohen, J. A Power Primer. Psychol. Bull. 1992, 112, 155-159.

(90) U.S. EPA. Causal Analysis/Diagnosis Decision Information System (CADDIS): About Stressors. https://www.epa.gov/caddisvol2/learn-about-stressors (accessed Dec 1, 2020).

(91) Weiner, R.; Matthews, R. Environmental Engineering, 4th ed.; Elsevier Science, 2003.

(92) Fair, G. M. The Dissolved Oxygen Sag: An Analysis. Sewage Works J. 1939, 11, 445-461.

(93) Malaysia Environmental Quality Report-River Water Quality; Department of Environment, 2015.

(94) Zhou, N.; Westrich, B.; Jiang, S.; Wang, Y. A Coupling Simulation Based on a Hydrodynamics and Water Quality Model of the Pearl River Delta, China. J. Hydrol. 2011, 396, 267-276.

(95) Benedini, M.; Tsakiris, G. Water Quality Modelling for Rivers and Streams; Springer, 2013.

(96) Fonseca, A.; Botelho, C.; Boaventura, R. A. R.; Vilar, V. J. P. Integrated Hydrological and Water Quality Model for River Management: A Case Study on Lena River. Sci. Total Environ. 2014, 485-486, 474-489.

(97) Jong, M.-C.; Harwood, C. R.; Blackburn, A.; Snape, J. R.; Graham, D. W. Impact of Redox Conditions on Antibiotic Resistance Conjugative Gene Transfer Frequency and Plasmid Fate in Wastewater Ecosystems. Environ. Sci. Technol. 2020, 54, 14984-14993.

(98) Vellidis, G.; Barnes, P.; Bosch, D. D.; Cathey, A. M. Mathematical Simulation Tools for Developing Dissolved Oxygen TMDLs. Trans. ASABE 2006, 49, 1003-1022.

(99) Chowdhury, A. S.; Call, D. R.; Broschat, S. L. PARGT: A Software Tool for Predicting Antimicrobial Resistance in Bacteria. Sci. Rep. 2020, 10, No. 11033. 
(100) Her, H. L.; Wu, Y. W. A Pan-Genome-Based Machine Learning Approach for Predicting Antimicrobial Resistance Activities of the Escherichia coli Strains. Bioinformatics 2018, 34, i89-i95.

(101) Li, X.; Liang, B.; Xu, D.; Wu, C.; Li, J.; Zheng, Y. Antimicrobial Resistance Risk Assessment Models and Database System for Animal-Derived Pathogens. Antibiotics 2020, 9, No. 829.

(102) Gothwal, R.; Shashidhar, T. Antibiotic Pollution in the Environment: A Review. Clean: Soil, Air, Water 2015, 479-489.

(103) Knapp, C. W.; Engemann, C. A.; Hanson, M. L.; Keen, P. L.; Hall, K. J.; Graham, D. W. Indirect Evidence of Transposon-Mediated Selection of Antibiotic Resistance Genes in Aquatic Systems at LowLevel Oxytetracycline Exposures. Environ. Sci. Technol. 2008, 42, 5348-5353.

(104) Global Antimicrobial Resistance Surveillance System (GLASS) Report: Early Implementation 2020; WHO, 2020. 